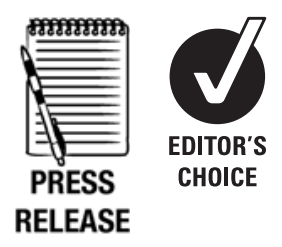

- Additional tables and appendices are published online only. To view these files please visit the journal online (http:// oem.bmj.com/content/69/2. toc).

'Department of Epidemiology, Lazio Regional Health Service, Rome, Italy

${ }^{2}$ Institute for Risk Assessment Sciences, University of Utrecht, Utrecht, The Netherlands ${ }^{3}$ Netherlands Applied Research Organization (TNO), TA Utrecht, The Netherlands

${ }^{4}$ Italian Institute for Environmental Protection and Research (ISPRA), Rome, Italy

\section{Correspondence to}

Giulia Cesaroni, Department of Epidemiology, Lazio Regional Health Service, Via S. Costanza 53, 00198 Rome, Italy; cesaroni@asplazio.it

Accepted 8 June 2011 Published Online First 7 August 2011

\title{
Health benefits of traffic-related air pollution reduction in different socioeconomic groups: the effect of low-emission zoning in Rome
}

\author{
Giulia Cesaroni, ${ }^{1}$ Hanna Boogaard, ${ }^{2}$ Sander Jonkers, ${ }^{3}$ Daniela Porta, ${ }^{1}$ Chiara Badaloni, \\ Giorgio Cattani, ${ }^{4}$ Francesco Forastiere, ${ }^{1}$ Gerard Hoek ${ }^{2}$
}

\section{ABSTRACT}

Objectives Few studies have assessed the effects of policies aimed to reduce traffic-related air pollution. The aims of this study were to evaluate the impact, in terms of air quality and health effects, of two low-emission zones established in Rome in the period 2001-2005 and to assess the impact by socioeconomic position (SEP) of the population.

Methods We evaluated the effects of the intervention on various stages in the full-chain model, that is, pressure (number and age distribution of cars), emissions, $\mathrm{PM}_{10}$ and $\mathrm{NO}_{2}$ concentrations, population exposure and years of life gained (YLG). The impact was evaluated according to a small-area indicator of SEP Results During the period 2001-2005, there was a decrease in the total number of cars $(-3.8 \%), \mathrm{NO}_{2}$ and $\mathrm{PM}_{10}$ emissions and concentrations (from 22.9 to $17.4 \mu \mathrm{g} / \mathrm{m}^{3}$ for $\mathrm{NO}_{2}$ and from 7.8 to $6.2 \mu \mathrm{g} / \mathrm{m}^{3}$ for $\mathrm{PM}_{10}$ ), and in the residents' exposure. In the two lowemission zones, there was an additional decrease in air pollution concentrations $\left(\mathrm{NO}_{2}:-4.13\right.$ and $-2.99 \mu \mathrm{g} / \mathrm{m}^{3}$; $\mathrm{PM}_{10}$ : -0.70 and $-0.47 \mu \mathrm{g} / \mathrm{m}^{3}$ ). As a result of the policy, 264522 residents living along busy roads gained 3.4 days per person (921 YLG per 100000 ) for $\mathrm{NO}_{2}$ reduction. The gain was larger for people in the highest SEP group (1387 YLG per 100000 ) than for residents in the lowest SEP group (340 YLG per 100000).

Conclusion The traffic policy in Rome was effective in reducing traffic-related air pollution, but most of the health gains were found in well-off residents.

The literature on the detrimental effects of traffic air pollution on health has grown considerably in the last decade. ${ }^{1}$ Recently, the debate on the possible differential effects of air pollution exposure in different socioeconomic groups of the population has raised environmental justice concerns. ${ }^{2-4}$ In American and European cohort studies, educational level has been shown to modify the effect of exposure to particulate matter on mortality, with higher risks among people with lower educational level..$^{5-11}$

According to the Italian Institute for Environmental Protection and Research, motorised road traffic is the source of $44 \%$ of the $\mathrm{NO}_{2}$ and $26 \%$ of the $\mathrm{PM}_{10}$ emissions in Italy. ${ }^{12}$ In the city of Rome, these percentages raise to $80 \%$ and $52 \%{ }^{13}$

The European Union has set standards for ambient air quality to protect the health of European citizens. National policies related to air quality are focused on economic instruments like

\section{What this paper adds}

- Few studies have evaluated the impact of traffic policies on both air quality and health.

- Policies affect the intervention zones, and reductions in $\mathrm{NO}_{2}$ are larger than those in $\mathrm{PM}_{10}$.

- In Rome, the low-emission zoning had a small impact on years of life gained at the city level but had a large impact in the intervention area.

- The high socioeconomic position population benefited more from the policy than low socioeconomic groups.

- The low-emission zone in Rome was beneficial from a public health point of view for all socioeconomic groups of the population, but it also exacerbated social inequalities.

fuel taxation and subsidies to replace old with new less-polluting vehicles. At the local level, traffic measures are being implemented like congestion charges, environmental zoning designed to limit traffic of polluting vehicles, monetary subsidies to accelerate replacement of old cars and measures to promote public transport and cycling.

Studies that have evaluated the effects of traffic policies are still limited; the majority of them indicate a decrease in emissions or concentrations of air pollutants, but only a few have analysed the effects on both air quality and health. ${ }^{14-21}$ The traffic congestion reduction during the 1996 Olympic Games in Atlanta was associated with a decreased traffic density, a reduction in ozone concentrations, lower rates in childhood asthma events and a small decrease in emergency department visits ${ }^{17}{ }^{18}$; similar results were reported during the 2002 Summer Asian Games in South Korea. ${ }^{19}$ Using modelling and GIS data, Tonne et al. ${ }^{14}$ estimated a small reduction in $\mathrm{NO}_{2}$ and $\mathrm{PM}_{10}$ concentrations and a gain of 188 years of life per 100000 people after the Congestion Charging Zone (CCZ) introduced in London in 2003. After the implementation of road pricing policy in Stockholm, there was a $8.5 \%$ decrease in $\mathrm{NO}_{2}$ emissions, a $13 \%$ decrease in $\mathrm{PM}_{10}$ emissions and a gain of 206 years of life per 100000 people. ${ }^{20}$ Assuming the same concentration-response function (CRF) for low and high socioeconomic groups, the study conducted in London indicated that the 
congestion charging scheme was associated with a small reduction in socioeconomic inequalities in exposure to trafficrelated air pollution and in mortality. ${ }^{14}$

The aims of this study were to evaluate the impact, in terms of air quality and health effects, of the intervention implemented by the City Council of Rome (two low-emission zones) in the period 2001-2005 to reduce traffic-related air pollution and to examine whether the impact was different by socioeconomic position (SEP). We evaluated the sensitivity of the results by the use of a single or SEP-specific CRFs.

\section{METHODS}

This study was conducted within the INTARESE (Integrated Assessment of Health Risks of Environmental Stressors in Europe) project. $^{22}$ Briefly, INTARESE uses a full-chain approach to assess the effects of policies on indicators of health. Policies are evaluated on the basis of mean population health gain and also on indicators of the social distribution of that gain. We evaluated the effects of policy intervention on various stages of the full-chain model, that is, pressures (number of cars, age distribution of cars, number of kilometre driven), emissions, $\mathrm{PM}_{10}$ and $\mathrm{NO}_{2}$ concentrations, population exposure to $\mathrm{PM}_{10}$ and $\mathrm{NO}_{2}$ by SEP of the residents and health effects.

\section{The urban layout of Rome}

Rome is the largest Italian city, with 2.7 million inhabitants in a $1285 \mathrm{~km}^{2}$ area. The urban area is divided into five concentric circular zones, corresponding with different levels of urbanisation, population density and transportation. The historical centre, which corresponds to the limited traffic zone (LTZ) (55000 inhabitants over an area of $6 \mathrm{~km}^{2}$ ), shows the highest concentration of business activity in Rome. The central railway ring area (397000 inhabitants, $39 \mathrm{~km}^{2}$ ) has the highest population density and represents a great deal of business activity. The semi-central Green Strip area (944000 inhabitants, $111 \mathrm{~km}^{2}$ ) is characterised by medium business density and high population density. The peripheral area covers the rest of the city that falls within the external ring road (Main Ring Road) (729000 inhabitants, $189 \mathrm{~km}^{2}$ ). Business and residential density are lower than in the previous areas. The last area includes all the districts outside the main ring road (626000 inhabitants). Unfortunately, the radial system of public transportation has not been sufficiently developed. In 2001, pedestrian and public transport shared only $40 \%$ (20\% each) of the total mobility, while $60 \%$ of the trips were by private transport; in the historical centre, traffic is $34 \%$ pedestrian, $29 \%$ public transport and $37 \%$ private transport (including cars, motorcycles and mopeds). The map of Rome indicating the circular zones and high-traffic roads (HTRs) (>10000 vehicles per day) is shown in figure 1 .

\section{The intervention}

The intervention was implemented in two city areas: the central LTZ and the railway ring. Driving in the LTZ, since October 2001, has been prohibited to all vehicles from 06:30 till 18:00 from Monday through Friday and from 14:30 till 18:00 on Saturday. The system uses fully automatic checks with cameras that record vehicles that enter and exit the zone, with expensive fines automatically issued to those who enter illegally. Only authorised vehicles (residents' cars, commercial vehicles and public transport vehicles) can enter at any time.

In the railway ring area, the intervention was implemented between 2002 and 2003 and enforced using expensive fines. Starting in January 2002, old diesel vehicles were not allowed in the area (during the daytime); starting in July 2002, only

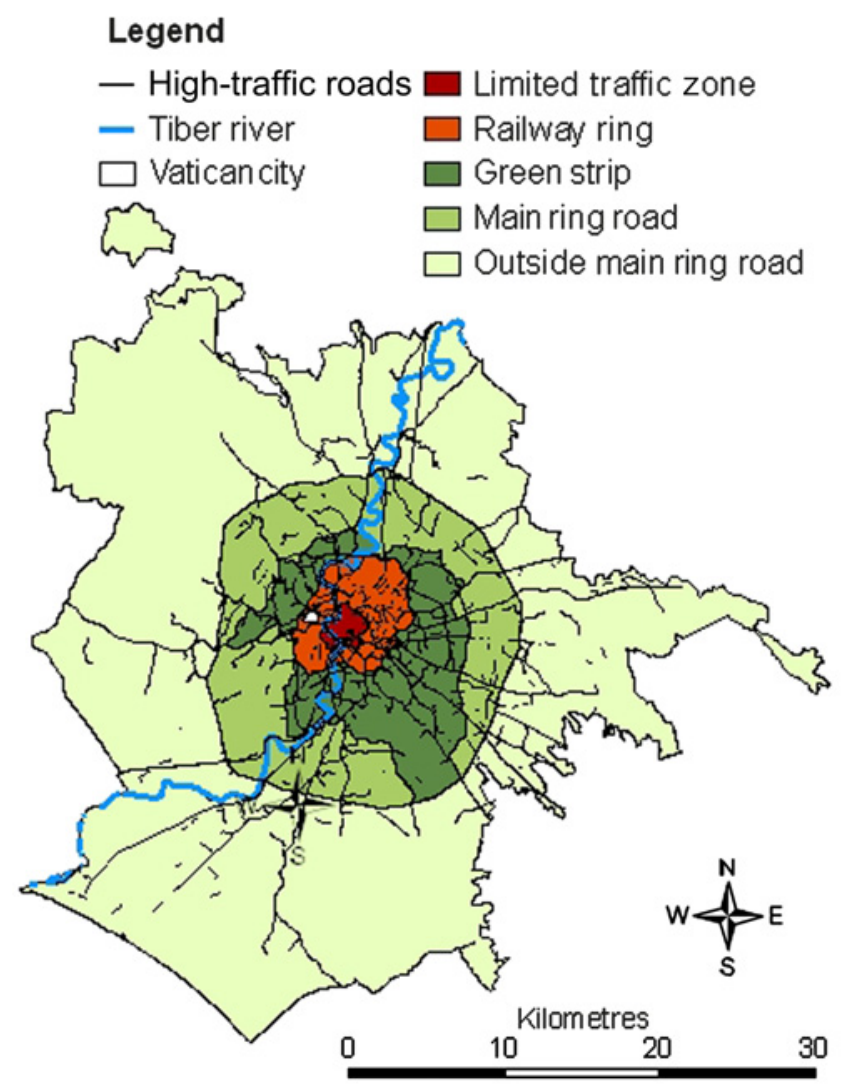

Figure 1 Map of Rome with the circular zones and high-traffic roads (>10000 vehicles per day).

vehicles with a catalytic converter were allowed in the area (during the daytime), and from January 2003 at any time of day.

The overall goal of the policy was to reduce the number of private vehicles in the centre, to encourage the use of public transport and to facilitate replacement of old heavily polluting vehicles. The intervention has been coupled with national policies to provide monetary incentives to buy new less-polluting vehicles.

\section{Pressures}

The impact of the policy on number and type of vehicles was evaluated using data from 2001 to 2005 derived from the national automobile association (http://www.aci.it). The data were of total number of vehicles by type (moped, motorcycles, cars, buses, light duty vehicles, heavy duty vehicles), type of fuel (gasoline, diesel, LPG or methane) and Euro classification categories (Euro 0, 1, 2, 3, 4) city-wide. The Euro classification category corresponds to the level of emissions of motor vehicles indicated by European directives. ${ }^{23}$ To evaluate whether these indicators changed because of the intervention or due to autonomous time trends, we have compared the Rome indicators with regional statistics (central Italy without Rome).

\section{Policy evaluation}

The evaluation of the policy was made by considering a diverse traffic composition in the area of intervention compared to the other areas of the city. This was done because the intervention prohibited access of the most pollutant vehicles to the lowemission zones. First, a 'without policy scenario' was considered on the basis of the known car fleet of the city, without taking into account the policy. Second, an 'optimistic scenario' was evaluated assuming that there would no longer be any Euro 
0 cars in the railway ring area, all would be replaced with Euro 4 cars. Finally, a 'pessimistic scenario' was evaluated that considered $10 \%$ of the Euro 0 cars were still circulating within the railway ring area, and $90 \%$ of the Euro 0 cars in the target area were replaced by Euro 1-4 type cars (according to the proportion of the city car fleet in 2005).

\section{Emissions}

A software program (Copert III) developed for the European Environmental Agency was used for the calculation of emissions from the road transport sector. ${ }^{23}$ Air pollution emission factors were applied to all vehicles in circulation between 2001 and 2005 in order to determine average emission values for each year. For the year 2005, three sets of average fleet emission values were estimated: the without policy scenario emissions, the optimistic scenario emissions and the pessimistic scenario emissions. In appendix 1 (online only), we describe in detail the methods used to estimate these emission factors.

\section{Concentration of air pollutants}

Concentrations were calculated only for HTRs ( $>10000$ vehicles per day) using a local-scale dispersion model. We assumed that background concentrations were not affected by the policy. Emission factors, traffic volume and street geometry properties were used as input for the dispersion modelling of $\mathrm{PM}_{10}$ and $\mathrm{NO}_{2}$ at the street level with the CAR-2 model. ${ }^{24} 25$ The CAR-2 model assesses the contribution of traffic on a specific street for each pollutant. The model does not take nearby streets into account. The $\mathrm{NO}_{2}$ contribution is calculated from the $\mathrm{NOx}$ contribution, using the background ozone concentration and an empirical chemical conversion formula. To calculate the concentration contribution from road traffic, the CAR-2 model was applied to calculate the normalised concentration contribution, that is, the average concentration contribution per vehicle. It was then multiplied by the number of vehicles per day on a specific street in order to get the concentration contribution in micrograms per cubic metre, and it was calculated for 1560 distinct road characteristics (5 road types, 3 tree densities, 26 widths and 4 traffic compositions).

The City Council of Rome provided the traffic data for all major roads in Rome as of 2005 (6585 road segments, 26\% of all roads in Rome), including the HTRs (2228 segments, $9.7 \%$ of all roads in Rome). For each HTR segment, we had data on the number of vehicles circulating, the circular zone and the neighbourhood in which it is located, the segment's width, length, the street type and tree density. More detailed methods are available in appendix 2 (online only).

We collected and stored all geographical variables using ArcGis 9.1 (ESRI, Redlands, California, USA). We used the Word Geodetic System of 1984 with the Universal Transverse Mercator $33 \mathrm{~N}$ as the coordinate system and map projection (http://www.teleatlas.com).

\section{Population exposures}

Data on residents of Rome in 2001 and 2005 were obtained from the Municipal Registry Office. We geocoded each residential address using the Italian road network (Tele Atlas, Italy), and for each address, we measured the distance to the nearest HTR. We considered the 264522 residents living at a distance of $\leq 50 \mathrm{~m}$ to the nearest HTR as the study population. We also assessed the exposure of the 1077460 subjects who live at a distance $\leq 150 \mathrm{~m}$ to the nearest HTR. For each subject, we assigned the exposure estimate to traffic-related $\mathrm{PM}_{10}$ and $\mathrm{NO}_{2}$ produced by the CAR-2 model.
As an index of SEP, a 5-level index by census block (average population: 500 subjects) was used. ${ }^{26}$ The study population was divided by the residential zones and by SEP.

\section{CRFs for $\mathrm{PM}_{10}$ and $\mathrm{NO}_{2}$}

We assumed a linear relationship between the air pollutants and associated health effects since most epidemiological studies on large populations have been unable to identify a threshold concentration below which ambient air pollutants have no effect on morbidity and mortality. ${ }^{27}$ CRFs were derived from cohort studies from both the USA and Europe. ${ }^{6} 1028-35$ Estimates were derived from a meta-analysis with a fixed-effects inverse-variance weighted method. ${ }^{36}$ (See online table 1 for the individual studies.) Summary CRFs expressed per $10 \mu \mathrm{g} / \mathrm{m}^{3}$ for $\mathrm{PM}_{2.5}$ and $\mathrm{NO}_{2}$ were 1.06 (95\% CI 1.03 to 1.09$)$ and $1.06(95 \%$ CI 1.04 to 1.08), respectively. As the policy affects tailpipe emissions only, which are in the fine particle mode, the change in $\mathrm{PM}_{10}$ modelled by the dispersion involves particles smaller than $2.5 \mu \mathrm{m}$. We therefore used the CRF for $\mathrm{PM}_{2.5}$ directly and multiplied that with the change in modelled $\mathrm{PM}_{10}$ (the model did not calculate $\mathrm{PM}_{2.5}$ ).

In addition, we calculated three different CRFs based on three educational levels (primary school, secondary school, and post secondary). The summary estimates were based on the original extended ACS study, the reanalysis of the six-city study and the Dutch cohort study (see online table 2). ${ }^{6} 89$ The summary CRFs expressed per $10 \mu \mathrm{g} / \mathrm{m}^{3}$ for $\mathrm{PM}_{2.5}$ were 1.10 (95\% CI 1.05 to 1.16$), 1.08$ (95\% CI 1.03 to 1.13$)$ and 1.05 (95\% CI 1.02 to 1.09) for low, average and high SEP categories, respectively. There were insufficient studies to derive SEP-specific CRFs for $\mathrm{NO}_{2}$.

\section{Quantification of mortality impacts}

The impact the traffic policies had on mortality in 2005 according to the optimistic and pessimistic scenarios were estimated in terms of years of life gained (YLG). ${ }^{37}$ We applied CRFs to all $\geq 30$-year-old residents who live at a distance $\leq 50 \mathrm{~m}$ from HTRs. Baseline mortality rates by 1 -year age groups of the Rome population were used. When the analysis was conducted by SEP, the SEP-specific mortality rates for Rome were considered. Population exposure to traffic-related $\mathrm{PM}_{10}$ and $\mathrm{NO}_{2}$ in 2001 and in 2005 (with and without application of the policy) was calculated by circular zone and SEP group. For the purpose of comparing circular zones and SEP groups, YLG were calculated per 100000 people over 15 years following the implementation of the intervention (2006-2020).

Sensitivity analyses were conducted to evaluate the robustness of the results. First, we used different CRFs by SEP for $\mathrm{PM}_{10}$ exposure. Then, we considered not only the subjects living along the HTRs (for whom exposure assessment was more straightforward with the CAR-2 model) but also for the entire population who live at a distance of $\leq 150 \mathrm{~m}$ of an HTR. We estimated exposure to traffic-related $\mathrm{PM}_{10}$ and $\mathrm{NO}_{2}$ as follows:

1. For people living at a distance of $\leq 50 \mathrm{~m}$ of an HTR, we assigned the value exactly estimated with the CAR-2 model.

2. For people living at a distance between 50 and $100 \mathrm{~m}$ of an HTR, a factor of 0.7 was applied to the estimated contribution of the CAR-2 model. This was done based on experimental observations of the rapid decay of these pollutants from the source. ${ }^{2}$

3. For people living at a distance between 100 and $150 \mathrm{~m}$ of an HTR, a factor of 0.5 was applied to the estimated contribution of the CAR-2 model of the closest HTR. 


\section{RESULTS}

\section{Traffic composition 2001-2005 in Rome}

The total number of cars decreased slightly in Rome between 2001 and 2005 (-3.8\%), but this was also observed in central Italy excluding Rome (-13.1\%) and hence is likely not a result of the policy. The decrease of Euro 0 petrol cars and the increase of Euro 3 cars were substantially greater in Rome than in central Italy, which may be an effect of the policy or may reflect other differences between Rome and central Italy (online table 3).

\section{Emission factors}

We calculated emission factors by vehicle type and year according to the two scenarios (online table 4). In the Without policy scenario, the average emission factors for the fleet of public buses, heavy and light duty vehicles, mopeds, motorcycles and passenger cars decreased in Rome between 2001 and 2005, and the effect was stronger for $\mathrm{NO}_{2}$ (for cars: from 1.06 to $0.73 \mathrm{~g} / \mathrm{km}$ ) than for $\mathrm{PM}_{10}$ (for cars: from 0.079 to $0.067 \mathrm{~g} / \mathrm{km}$ ). As a result of the policy, under the optimistic scenario in 2005, there was a further reduction of the emission factors for passenger cars in the railway ring area $\left(\mathrm{NO}_{2}: 0.45 \mathrm{~g} / \mathrm{km},-58 \%\right.$; $\left.\mathrm{PM}_{10}: 0.053 \mathrm{~g} / \mathrm{km} ;-33 \%\right)$.

\section{Changes in concentrations}

When emission factors were used in the CAR-2 model, the traffic-related contribution to $\mathrm{PM}_{10}$ and $\mathrm{NO}_{2}$ was estimated for each circular zone (Table 1). The traffic contribution to $\mathrm{NO}_{2}$ and $\mathrm{PM}_{10}$ decreased from 2001 to 2005 (without policy) by $24 \%$ and $21 \%$, respectively. In 2005 , there was an additional small reduction in the average concentration of $\mathrm{NO}_{2}(-2 \%)$ and $\mathrm{PM}_{10}$ $(-1 \%)$ related to the intervention (both under the optimistic and pessimistic scenarios) across the city, assuming no changes outside the intervention area. The impact was sizeable when considering the intervention area, with a further $23 \%$ reduction in $\mathrm{NO}_{2}$ and $10 \%$ in $\mathrm{PM}_{10}$ in the railway ring area, under the optimistic scenario.

The difference between the two scenarios was slight. This was due to the large difference in Euro 0 emission factors compared to Euro 1-4. Therefore, the main impact on concentration contributions resulted from the removal of Euro 0 vehicles from the roads. The class of the replacement car was of lesser importance.

\section{Changes in population exposure and related health effects}

Table 2 shows the average population-weighted annual exposure to traffic-related $\mathrm{NO}_{2}$ and $\mathrm{PM}_{10}$ for 264522 subjects living along HTRs and their impact in terms of YLG.
Due to the changes in the car fleet, without taking account of the policy, the average exposure decreased from 2001 to 2005 (from 24.1 to $18.4 \mu \mathrm{g} / \mathrm{m}^{3}$ for $\mathrm{NO}_{2}$, and from 8.7 to $6.8 \mu \mathrm{g} / \mathrm{m}^{3}$ for $\mathrm{PM}_{10}$ ). This decrease affected much of the central part of the city (residents along an HTR outside the main ring road had a decrease of only $3.17 \mu \mathrm{g} / \mathrm{m}^{3}$ of exposure to $\mathrm{NO}_{2}$ compared to an average of $5.54 \mu \mathrm{g} / \mathrm{m}^{3}$ for residents in the city centre).

The intervention had an impact on the exposure of the residents in Rome living along HTRs: in the optimistic scenario for $\mathrm{NO}_{2}$, there was a further overall decrease of $0.78 \mu \mathrm{g} / \mathrm{m}^{3}$ due to an additional decrease of 3.27 and $4.02 \mu \mathrm{g} / \mathrm{m}^{3}$ in the railway ring and in the LTZ areas, respectively.

In Rome, $22 \%$ of residents along HTRs are also in a high SEP area, while only $14 \%$ are in a low SEP area. There were no differences between baseline concentrations in different socioeconomic groups, and the average $\mathrm{NO}_{2}$ exposure decreased from 2001 to 2005 by $5-6 \mu \mathrm{g} / \mathrm{m}^{3}$ in all groups. However, considering the policy, the highest $\mathrm{NO}_{2}$ difference was observed in the highest socioeconomic group $\left(-1.21 \mu \mathrm{g} / \mathrm{m}^{3}\right.$ vs $-0.29 \mu \mathrm{g} / \mathrm{m}^{3}$ in the lowest socioeconomic group under the optimistic scenario).

All residents along HTRs were predicted to gain 2436 years, that is, 921 years of life per 100000 (average gain per person: 3.4 days) from the optimistic scenario reduction in $\mathrm{NO}_{2}$, and 1812 years, that is, 685 years per 100000 (average gain per person: 2.5 days) were gained from the pessimistic scenario. This gain was seen in the railway ring and LTZ areas (with 15 and 19 days per person, respectively). The highest socioeconomic group benefited most from the policy (1387 YLG vs 340 YLG per 100000 in the optimistic scenario due to the reduction in $\mathrm{NO}_{2}$ exposure). For subjects living along an HTR, the optimistic and pessimistic reductions in $\mathrm{PM}_{10}$ exposure resulted in 153 YLG and 130 YLG per 100000 , respectively, substantially less than estimated for $\mathrm{NO}_{2}$, but consistently four times greater for the highest compared to the lowest socioeconomic group.

Table 3 shows the impacts of $\mathrm{PM}_{10}$ air pollution on YLG in Rome on the population living along an HTR by SEP using SEPspecific CRFs. The difference in the health gains seen in high and low SEP groups is smaller than that shown in table 2 . The greatest gain was obtained by the two highest socioeconomic groups, but the social gradient of the effect was attenuated compared to the results we obtained using a single CRF.

Table 4 shows the population-weighted exposure to trafficrelated $\mathrm{NO}_{2}$ and $\mathrm{PM}_{10}$ for those living at a distance $\leq 150 \mathrm{~m}$ of HTRs. This illustrates the potential for additional health gains for a larger population living near $(n=1077460)$ but not necessarily on an HTR ( $\mathrm{n}=264522)$. The gain in life expectancy was due to the reduction in the average population-weighted annual

Table 1 Modelled average traffic contribution along HTRs (>10000 vehicles circulating per day) to the annual average of $\mathrm{NO}_{2}$ and $\mathrm{PM}_{10}$ concentrations (in micrograms per cubic metre) by circular zone in Rome

\begin{tabular}{|c|c|c|c|c|c|c|c|c|c|c|c|c|}
\hline Circular zone & $\begin{array}{l}\text { Number of } \\
\text { segments with } \\
\text { traffic data }\end{array}$ & $\begin{array}{l}\text { Length of } \\
\text { segments (m) }\end{array}$ & $\begin{array}{l}\text { Number of } \\
\text { HTR segments }\end{array}$ & $\begin{array}{l}\text { Length of HTR } \\
\text { segments }(m)\end{array}$ & \multicolumn{2}{|l|}{2001} & \multicolumn{2}{|c|}{$\begin{array}{l}2005 \text { without } \\
\text { policy } \\
\text { scenario }\end{array}$} & \multicolumn{2}{|c|}{$\begin{array}{l}2005 \text { with } \\
\text { optimistic } \\
\text { policy } \\
\text { scenario }\end{array}$} & \multicolumn{2}{|c|}{$\begin{array}{l}2005 \text { with } \\
\text { pessimistic } \\
\text { policy } \\
\text { scenario }\end{array}$} \\
\hline Outside main ring & 2004 & 1323052 & 543 & 463192 & 21.3 & 6.8 & 16.2 & 5.5 & 16.2 & 5.5 & 16.2 & 5.5 \\
\hline Main ring & 1147 & 541428 & 459 & 214046 & 22.9 & 7.6 & 17.4 & 6.1 & 17.4 & 6.1 & 17.4 & 6.1 \\
\hline Green strip & 1584 & 472273 & 710 & 202360 & 26.3 & 9.7 & 20.2 & 7.6 & 20.2 & 7.6 & 20.2 & 7.6 \\
\hline Total & 6589 & 2665026 & 2228 & 979447 & 22.9 & 7.8 & 17.4 & 6.2 & 17.0 & 6.1 & 17.1 & 6.1 \\
\hline
\end{tabular}

We assumed that traffic composition only changed in the Railway ring and in the limited traffic zone.

HTR, high-traffic roads. 
Table 2 Changes in average population-weighted annual exposure to air pollution $\left(\mathrm{NO}_{2}\right.$ and $\mathrm{PM}_{10}$, in micrograms per cubic metre) and associated impacts as YLG according to circular zone and SEP in subjects living along HTRs

\begin{tabular}{|c|c|c|c|c|c|c|c|c|c|c|c|c|c|c|}
\hline & \multicolumn{2}{|l|}{2001} & \multicolumn{2}{|c|}{$\begin{array}{l}2005 \text { without } \\
\text { policy }\end{array}$} & \multicolumn{2}{|c|}{$\begin{array}{l}\text { Difference } \\
\text { with/without } \\
\text { policy 2005 } \\
\text { optimistic } \\
\text { scenario }\end{array}$} & \multicolumn{2}{|c|}{$\begin{array}{l}\text { Difference } \\
\text { with/without } \\
\text { policy } 2005 \\
\text { pessimistic } \\
\text { scenario }\end{array}$} & \multirow{2}{*}{$\begin{array}{l}\text { Residents } \\
2005 \text { along } \\
\text { HTR }\end{array}$} & \multirow{2}{*}{$\begin{array}{l}\text { Mortality rates } \\
\text { per } 100000 \\
\text { population }\end{array}$} & \multicolumn{2}{|c|}{$\begin{array}{l}\text { YLG per } \\
100000 \\
\text { during } \\
15 \text { years } \\
\text { optimistic } \\
\text { scenario }\end{array}$} & \multicolumn{2}{|c|}{$\begin{array}{l}\text { YLG per } \\
100000 \\
\text { during } \\
15 \text { years } \\
\text { pessimistic } \\
\text { scenario }\end{array}$} \\
\hline & $\mathrm{NO}_{2}$ & $\mathrm{PM}_{10}$ & $\mathrm{NO}_{2}$ & $\mathrm{PM}_{10}$ & $\mathrm{NO}_{2}$ & $\mathrm{PM}_{10}$ & $\mathrm{NO}_{2}$ & $\mathrm{PM}_{10}$ & & & $\mathrm{NO}_{2}$ & $\mathrm{PM}_{10}$ & $\mathrm{NO}_{2}$ & $\mathrm{PM}_{10}$ \\
\hline \multicolumn{15}{|l|}{ By circular zone } \\
\hline Outside main ring & 12.86 & 3.47 & 9.69 & 2.85 & 0 & 0 & 0 & 0 & 19681 & 924 & 0 & 0 & 0 & 0 \\
\hline Green strip & 26.76 & 9.85 & 20.6 & 7.69 & 0 & 0 & 0 & 0 & 123401 & 924 & 0 & 0 & 0 & 0 \\
\hline Railway ring & 23.49 & 9.07 & 17.84 & 7.01 & -3.27 & -0.54 & -2.42 & -0.45 & 59181 & 924 & 4109 & 671 & 3030 & 559 \\
\hline Limited traffic zone & 23.52 & 9.13 & 17.98 & 7.12 & -4.02 & -0.68 & -2.97 & -0.57 & 3029 & 924 & 5084 & 858 & 3731 & 693 \\
\hline \multicolumn{15}{|l|}{ By SEP } \\
\hline 1 (high) & 23.92 & 8.69 & 18.22 & 6.76 & -1.21 & -0.20 & -0.90 & -0.17 & 57733 & 854 & 1387 & 229 & 1031 & 194 \\
\hline 2 & 25.33 & 9.25 & 19.36 & 7.23 & -1.00 & -0.17 & -0.74 & -0.14 & 61174 & 933 & 1167 & 198 & 863 & 163 \\
\hline
\end{tabular}

Baseline mortality rates standardised for age using the total Rome population of 2005. Pre-post differences of 2005 based on population-weighted average concentrations of address data of 264522 subjects. We have assumed that the difference results in a reduction in hazards for the years 2005 till 2019 based on the $\mathrm{CRF}$ of 1.06 per $10 \mu \mathrm{g} / \mathrm{m}^{3}$ in $\mathrm{NO} \mathrm{O}_{2}$ or PM $\mathrm{M}_{10}$. These $\mathrm{CRFs}$ were applied for people aged $\geq 30$ years. HTR: $>10000$ vehicles circulating per day.

CRF, concentration-response function; HTR, high-traffic road; SEP, socioeconomic position; YLG, years of life gained.

exposure in the LTZ and in the railway ring areas. These resulted in 686 YLG per 100000 for $\mathrm{NO}_{2}$ reduction and 116 YLG per 100000 for $\mathrm{PM}_{10}$ reduction in the population living at a distance of $\leq 150 \mathrm{~m}$ of an HTR. Considering the city as a whole, the gain was greater in the highest than in the lowest SEP group. Patterns observed with respect to zone and SEP were as observed for the HTR population.

\section{DISCUSSION}

The policy resulted in $33 \%$ and $58 \%$ lower $\mathrm{PM}_{10}$ and $\mathrm{NO}_{2}$ emissions from passenger cars in the intervention area. Changes in concentrations of $\mathrm{NO}_{2}$ and $\mathrm{PM}_{10}$ were modest city-wide $\left(<1 \mu \mathrm{g} / \mathrm{m}^{3}\right)$, but larger reductions were estimated in the intervention area. Predicted changes were larger for $\mathrm{NO}_{2}$ than for $\mathrm{PM}_{10}$, consistent with the known impact of traffic on this pollutant. $^{13} 14$

Consistent with the modest change in air pollution concentrations, the policy resulted in small gains in life expectancy at the city level ( 3.4 days on average per person living at a distance of $\leq 50 \mathrm{~m}$ from HTR). Life expectancy gains were substantially larger when they were calculated for the population in the intervention area (19 and 15 days gained per resident in the LTZ and in the railway ring areas, respectively). Because of the geographical distribution of SEP within the city, the decrease in annual air pollution exposure was larger in the highest socioeconomic group. Despite higher baseline mortality rates in the lowest socioeconomic group, the gain in life expectancy was more substantial in the high socioeconomic groups. Socioeconomic differences were less marked in life expectancy gains when we used SEP-specific CRFs for $\mathrm{PM}_{10}$.

The small gain at the city level is very likely an underestimation of the true impact of the policy change. In fact with the modelling tools available, we only evaluated impacts of the policy on HTRs, assuming that there was no impact on urban background levels. Even though the impact on background conditions was probably very small, there are many people who are affected by background levels. Moreover, due to constraints in emission data, air pollution dispersion models and CRFs, we limited the assessment to $\mathrm{NO}_{2}$ and $\mathrm{PM}_{10}$. These pollutants are not the most specific indicators of the complex mixture of emissions from motorised traffic. The impact of the intervention on concentrations of ultrafine particles, soot and possible polycyclic aromatic hydrocarbons may have been more substantial. Furthermore, we only assessed impacts on residents and ignored

Table 3 Changes in average population-weighted annual exposure to air pollution $\left(\mathrm{PM}_{10}\right)$ and associated impacts as YLG according to SEP in subjects living along HTR using SEP-specific CRFs

\begin{tabular}{|c|c|c|c|c|c|c|}
\hline & Population & $\begin{array}{l}\text { Mortality rates } \\
\text { per } 100000 \text { population }\end{array}$ & $\begin{array}{l}\text { Pre-post difference } \\
\text { optimistic scenario }\left(\mathrm{PM}_{\mathbf{1 0}}\right)\end{array}$ & $\begin{array}{l}\text { Pre-post difference } \\
\text { pessimistic scenario }\left(\mathrm{PM}_{10}\right)\end{array}$ & $\begin{array}{l}\text { YLG per } 100000 \\
\text { during } 15 \text { years } \\
\text { optimistic scenario }\end{array}$ & $\begin{array}{l}\text { YLG per } 100000 \\
\text { during } 15 \text { years } \\
\text { pessimistic scenaric }\end{array}$ \\
\hline \multicolumn{7}{|l|}{ By SEP } \\
\hline 1 (high) & 57733 & 854 & -0.20 & -0.17 & 191 & 163 \\
\hline 2 & 61174 & 933 & -0.17 & -0.14 & 262 & 216 \\
\hline 3 & 63325 & 901 & -0.10 & -0.08 & 156 & 125 \\
\hline 4 & 45180 & 896 & -0.10 & -0.08 & 151 & 122 \\
\hline 5 (low) & 37110 & 1029 & -0.05 & -0.04 & 94 & 75 \\
\hline
\end{tabular}

Baseline mortality rates standardised for age using the total Rome population of 2005. Pre-post differences of 2005 based on population-weighted average concentrations of address data of 264522 subjects. We have assumed that the difference results in a reduction in hazards for the years 2005 till 2019 based on different CRFs for the different SEP groups. These CRFs were applied for people aged $\geq 30$ years. CRF of 1.05 for the highest SEP group, 1.08 for the three middle groups, and a CRF of 1.10 for the lowest group. HTR: $>10000$ vehicles circulating per day. CRF, concentration-response function; HTR, high-traffic road; SEP, socioeconomic position; YLG, years of life gained. 
Table 4 Changes in average population weighted annual exposure to air pollution $\left(\mathrm{NO}_{2}\right.$ and $\mathrm{PM}_{10}$, in micrograms per cubic metre) and associated impacts as YLG according to circular zone and SEP in residents within $150 \mathrm{~m}$ from HTRs

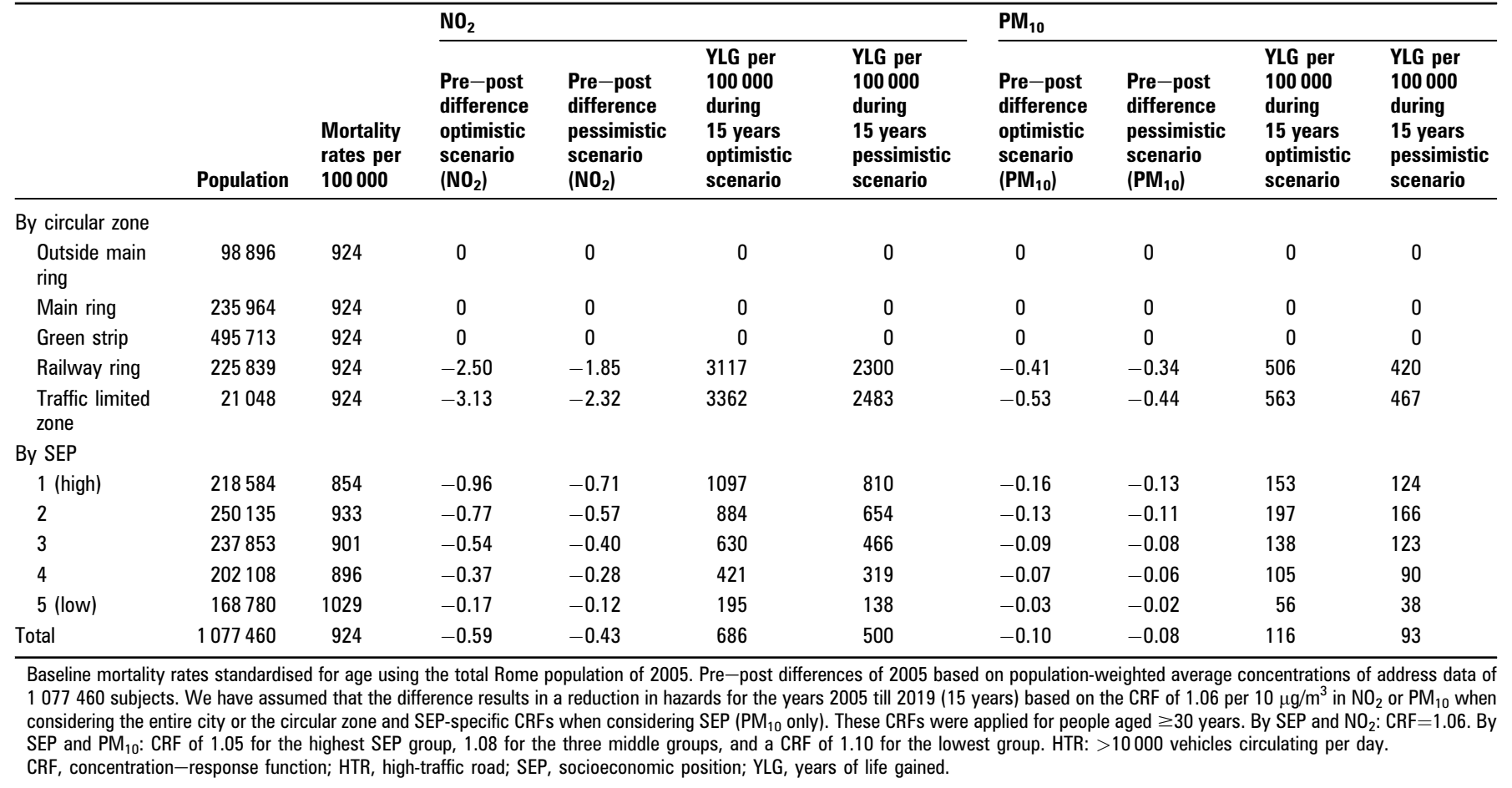

potential benefits to commuters/traffic participants and people who work in the city.

Similar to this evaluation, the impact on $\mathrm{NO}_{2}$ concentrations was more substantial than on $\mathrm{PM}_{10}$ both in London ${ }^{14}$ and in Stockholm congestion charge intervention. ${ }^{20}$ There the impact was also largely restricted to the city centres: in London, the change in $\mathrm{NO}_{2}$ concentration was 0.73 in the $\mathrm{CCZ}$ versus $0.07 \mu \mathrm{g} / \mathrm{m}^{3}$ in Greater London, while in Stockholm, the decrease in NOx annual mean contribution to total level of NOx from traffic emissions was reduced by $10 \%$ in the centre and only by $5.3 \%$ in Greater Stockholm.

The estimated benefits in life years gained with the London congestion charging scheme were 183 YLG in 10 years per 100000 residents of London's CCZ versus 26 YLG in 10 years per 100000 in Greater London. ${ }^{14}$ Similarly, the benefits of road pricing in Stockholm were 206 YLG per 100000 over 10 years. $^{20}$ The choice we made to evaluate the policies only on subjects living along an HTR makes our figures much higher than in the above-mentioned studies.

In contrast to the Rome intervention, the CCZ policy in London was more beneficial for the most deprived, a result of a larger decrease in concentrations and larger baseline rates for the more deprived. ${ }^{14}$ This illustrates that the relationship between SEP and air pollution exposure is not simple. Available evidence from the USA and Canada, as well as from some European studies, have reported that persons with lower SEP in general are exposed to higher air pollution levels. ${ }^{2}$ On the contrary, in Rome, wealthy residents are more likely to live in the city centre, and they are exposed more than disadvantaged groups of the population are at their place of residence to higher air pollution concentrations. ${ }^{26}$ Because the policy targeted the central area of the city, the people who profited more from the policy were wealthy. In other European studies also the highest air pollution levels are reported for persons with the highest SEP. ${ }^{28} 38$

This study has some limitations. The long-term effect expressed in YLG reflects many assumptions. ${ }^{39}$ We assumed unchanging mortality rates and a consistent and stable change in pollutants' concentration over 15 years. Moreover, the changes in exposure to air pollution probably do not immediately affect mortality rates (we assumed a lag 0 ). We applied CRFs derived from studies conducted in different settings. Given the harmful effects of air pollution exposure, which are related to mortality and also include, for example, high incidence and prognosis of cardiovascular and respiratory diseases, ${ }^{1}$ the benefits of low-emission zones are probably much greater than those we found. Finally, given the similar $\mathrm{PM}_{10}$ and $\mathrm{NO}_{2} \mathrm{CRF}$ coefficients and the greater decrease in $\mathrm{NO}_{2}$ than in $\mathrm{PM}_{10}$ we estimated, the impacts for the $\mathrm{NO}_{2}$ reduction were larger than those for PM. Although currently most health impact assessments in this area are based on PM, given the sensitivity of NOx to changes in traffic we would recommend using NOx together with PM for traffic-based evaluations (provided that double counting is excluded).

\section{CONCLUSIONS}

This study provides evidence that policies aimed at reducing traffic-related air pollution have beneficial effects: a decrease of emissions, of concentrations, of population exposure, and health gains. The socioeconomic distribution of these effects is not readily apparent and requires a thorough assessment in view of current concerns related to environmental justice.

Acknowledgements The authors thank Margaret Becker for her editorial assistance.

Funding This study was funded by the INTARESE project. INTARESE is a 5-year Integrated Project funded under the EU 6th Framework Programme-Priority 6.3 Global Change and Ecosystems (Contract No. 018385).

\section{Competing interests None.}

Contributors Each author has contributed to the conception and design of the work, the acquisition of data or the analysis of the data in a manner substantial enough to take public responsibility for it; each believes that the manuscript represents valid work; and each has reviewed the final version of the manuscript and approves it for publication. 
Provenance and peer review Not commissioned; externally peer reviewed.

\section{REFERENCES}

1. HEl panel on the Health Effects of Traffic-Related Air Pollution: Traffic-Related Air Pollution: A Critical Review of the Literature on Emissions, Exposure, and Health Effects. HEl Special Report 17. Boston, MA: Health Effect Institute, 2010.

2. Jerrett M. Global geographies of injustice in traffic-related air pollution exposure. Epidemiology 2009;20:231-3.

3. Laurent 0, Bard D, Filleul L, et al. Effect of socioeconomic status on the relationship between atmospheric pollution and mortality. J Epidemiol Community Health 2007:61:665-75.

4. O'Neill MS, McMichael AJ, Schwartz J, et al. Poverty, environment, and health: the role of environmental epidemiology and environmental epidemiologists. Epidemiology 2007:18:664-8.

5. Pope CA 3rd, Burnett RT, Thun MJ, et al. Lung cancer, cardiopulmonary mortality, and long-term exposure to fine particulate air pollution. JAMA 2002;287:1132-41.

6. Health Effects Institute. Reanalysis of the Harvard Six Cities Study and the American Cancer Society Study of Particulate Air Pollution and Mortality: A Special Report of the Institute's Particle Epidemiology Reanalysis Project. Cambridge, MA: Health Effects Institute, 2000.

7. Krewski D, Jerrett M, Burnett RT, et al. Extended follow-up and spatial analysis of the American Cancer Society study linking particulate air pollution and mortality. Res Rep Health Eff Inst 2009:5-114; discussion 115-36.

8. Beelen R, Hoek G, van den Brandt PA, et al. Long-term effects of traffic-related air pollution on mortality in a dutch cohort (NLCS-AIR Study). Environ Health Perspect 2008:116:196-202.

9. Miller KA, Siscovick DS, Sheppard L, et al. Long-term exposure to air pollution and incidence of cardiovascular events in women. N Engl J Med 2007;356:447-58.

10. Finkelstein MM, Jerrett $\mathrm{M}$, DeLuca $\mathrm{P}$, et al. Relation between income, air pollution and mortality: a cohort study. CMAJ 2003;169:397-402.

11. Finkelstein MM, Jerrett M, Sears MR. Environmental inequality and circulatory disease mortality gradients. J Epidemiol Community Health 2005:59:481-7.

12. ISPRA. http://www.areemetropolitane.sinanet.apat.it (accessed 9 Jul 2010).

13. Taurino $\mathbf{E}$, Caputo $\mathrm{A}$, De Lauretis R. Le emissioni in atmosfera. Qualità dell'ambiente urbano. ISPRA, 2009. http://www.areeurbane.apat.it/site/_files/Rapporto2009/ VI_Rapporto.pdf (accessed Jul 2010)

14. Tonne C, Beevers S, Armstrong B, et al. Air pollution and mortality benefits of the London Congestion Charge: spatial and socioeconomic inequalities. Occup Environ Med 2008;65:620-7.

15. Nuvolone D, Barchielli A, Forastiere F. Assessing the effectiveness of local transport policies for improvements in urban air quality and public health: a review of scientific literature. Epidemiol Prev 2009;33:79-87.

16. van Erp AM, Cohen AJ. HEl's Research program on the impact of actions to improve air quality: interim evaluation and future directions. Communication 14. Boston, MA: Health Effect Institute, 2009.

17. Friedman MS, Powell KE, Hutwagner L, et al. Impact of changes in transportation and commuting behaviors during the 1996 Summer Olympic Games in Atlanta on air quality and childhood asthma. JAMA 2001:285:897-905.

18. Peel JL, Klein M, Flanders WD, et al. Impact of Improved Air Quality During the 1996 Summer Olympic Games in Atlanta on Multiple Cardiovascular and Respiratory Outcomes. HEI Research Report 148. Boston, MA: Health Effects Institute, 2010.
19. Lee JT, Son JY, Cho YS. Benefits of mitigated ambient air quality due to transportation control on childhood asthma hospitalization during the 2002 summe Asian games in Busan, Korea. J Air Waste Manag Assoc 2007;57:968-73.

20. Johansson C, Bruman L, Forsberg B. The effects of congestions tax on air quality and health. Atmos Environ 2009;43:4843-54.

21. Sugiri D, Ranft U, Schikowski T, et al. The influence of large-scale airborne particle decline and traffic-related exposure on children's lung function. Environ Health Perspect 2006;114:282-8

22. Briggs DJ. A framework for integrated environmental health impact assessment of systemic risks. Environ Health 2008;7:61-77.

23. Ntziachristos L, Samaras Z. COPERT III. Computer programme to calculate emissions from road transport. Technical Report No 49 2000. European Environment Agency. http://www.eea.europa.eu/en/publications/Technical_report_No_49/ tech49.pdf (accessed Apr 2011).

24. Eerens HC, Sliggers CJ, van den Hout KD. The CAR model: The Dutch method to determine city street air quality. Atmos Environ 1993;27:389-99.

25. Jonkers S. Handleiding CARII, versie 6.1. TNO-rapport 2007-A-R0788/B. Apeldoorn: TNO Bouw en Ondergrond, 2007.

26. Cesaroni G, Badaloni C, Romano V, et al. Socioeconomic position and health status of people who live near busy roads: the Rome Longitudinal Study (RoLS). Environ Health 2010;9:41.

27. NEEDS. Deliverable 3.7-RS1b/WP3. A set of concentration-response functions. 2007. http://www.needs-project.org/2009/Deliverables/Rs1b\%20D3.7.pdf laccessed 19 Jul 2010)

28. Filleul L, Rondeau V, Vandentorren S, et al. Twenty five year mortality and air pollution: results from the French PAARC survey. Occup Environ Med 2005; 62:453-60

29. Nafstad P, Haheim LL, Wisloff T, et al. Urban air pollution and mortality in a cohort of Norwegian men. Environ Health Perspect 2004;112:610-15.

30. Gehring U, Heinrich J, Kramer U, et al. Long-term exposure to ambient air pollution and cardiopulmonary mortality in women. Epidemiology 2006:17:545-51.

31. Dockery DW, Pope CA 3rd, Xu X, et al. An association between air pollution and mortality in six U.S. cities. N Engl J Med 1993;329:1753-9.

32. Laden F, Schwartz J, Speizer FE, et al. Reduction in fine particulate air pollution and mortality: Extended follow-up of the Harvard Six Cities study. Am J Respir Crit Care Med 2006;173:667-72.

33. Pope CA 3rd, Thun MJ, Namboodiri MM, et al. Particulate air pollution as a predictor of mortality in a prospective study of U.S. adults. Am J Respir Crit Care Med 1995;151:669-74.

34. Jerrett M, Burnett RT, Ma R, et al. Spatial analysis of air pollution and mortality in Los Angeles. Epidemiology 2005;16:727-36.

35. Abbey DE, Nishino N, McDonnell WF, et al. Long-term inhalable particles and other air pollutants related to mortality in nonsmokers. Am J Respir Crit Care Med 1999;159:373-82.

36. DerSimonian R, Laird N. Meta-analysis in clinical trials. Control Clin Trials 1986; 7:177-88.

37. Brunekreef B, Miller BG, Hurley JF. The brave new world of lives sacrificed and saved, deaths attributed and avoided. Epidemiology 2007;18:785-8.

38. Hoek G, Brunekreef B, Goldbohm S, et al. Association between mortality and indicators of traffic-related air pollution in the Netherlands: a cohort study. Lancet 2002; 360:1203-9.

39. Miller BG, Hurley JF. Life table methods for quantitative impact assessment in chronic mortality. J Epidemiol Community Health 2003:57:200-6. 